\title{
A RETROSPECTIVE ON THE ASIA-PACIFIC REGIONAL CONFERENCE ON UNDERWATER CULTURAL HERITAGE
}

\author{
Michelle M. Damian* \\ Department of History, Monmouth College, IL 61462 USA \\ Email: mmddives@gmail.com
}

Published online: 30 July 2021

To cite this article: Damian, M. M. 2021. A retrospective on the Asia-Pacific Regional Conference on Underwater Cultural Heritage. International Journal of Asia Pacific Studies 17 (2): 169-192. https://doi.org/10.21315/ijaps2021.17.2.7

To link to this article: https://doi.org/10.21315/ijaps2021.17.2.7

\begin{abstract}
November 8th to 12th, 2011, marked the first targeted gathering of people involved in researching, managing, and developing underwater cultural heritage (UCH) in the Asia-Pacific region. Since then, the Asia-Pacific Regional Conference on Underwater Cultural Heritage (APCONF) has been convened every three years, providing a unique opportunity to bring together members of government agencies, universities, non-governmental organisations (NGOs), intergovernmental organisations (IGOs), museums, the private sector, and the wider community. Participants from over 35 countries have attended the conference, making it a truly international endeavour. The APCONF was created in part to promote awareness of UCH on a wider scale. As such, one of the primary directives of the inaugural conference was to ensure that all papers presented would be recorded in full in the official conference proceedings, so as to establish an ongoing archive of the critical work being done in this region. This article will examine the wider benefits of creating this regional network through the APCONF, arguing that it provides an important venue for face-to-face networking that can lead to additional collaborations, and contributes to the understanding of how the conference may evolve in the future. The fact that the APCONF is not tied to a specific membership base provides not only unusual flexibility but also financial and infrastructural unsurety. The conference is organised by a group of dedicated volunteers and funded almost entirely by donations. As we stop to consider the first
\end{abstract}


decade of the APCONF's achievements, we also need to determine the best ways to ensure its sustainable future success.

Keywords: Asia Pacific, maritime, UNESCO, underwater cultural heritage

\section{INTRODUCTION}

"Free exchange of information is our message to the world", claimed Mark Staniforth, the organiser of the inaugural APCONF (Asia-Pacific Regional Conference on Underwater Cultural Heritage) in 2011 (APCONF 2011). That message has been embraced and built upon in subsequent meetings of the triennial conference, which has welcomed nearly 400 participants from over 35 different countries cumulatively. While maritime archaeological studies and efforts to preserve underwater cultural heritage $(\mathrm{UCH})$ of the Asia-Pacific region ${ }^{1}$ have been growing in recent years, this conference was the first to bring together specialists from the region to exchange information with their peers. Additionally, from its inception, the organisers intended that there be a tangible product that would last beyond the conference dates and be freely accessible to a wide audience.

This article will provide a retrospective on the APCONF, exploring its origins and assessing its impact to date. In looking at the three past meetings and one planned in the future, I will outline the evolving organisation of the conference, from its inception as the brainchild of three archaeologists to the most recent formalisation of the roles and duties involved in the planning of the conference. We will explore the changing makeup of the conference participants and research foci over the past decade, which reflects the broadening nature of the field of maritime archaeology. UNESCO (United Nations Educational, Scientific and Cultural Organization) participation has also had an impact on the conference's content and support. In addition, we will consider the benefits of and challenges to the sustainable future success of the APCONF. There is no standing membership base associated with the conference, and the ramifications of this are significant on both conference organisation and funding.

By examining these aspects of the conference, I will argue that while the APCONF has had a distinct impact for maritime archaeologists in the Asia-Pacific region, it is currently at a crossroad as it considers how it can continue to best serve all interested parties. The conference from its inception was meant to be inclusive and accessible to researchers in the Asia-Pacific 
region, allowing opportunities for professional and avocational archaeologists at all levels to meet and forge connections. Those connections have resulted in multiple collaborative efforts in projects ranging from fieldwork to publications. Furthermore, the conference proceedings provide an enduring, open-access record of the meetings. Yet, the APCONF faces challenges of sustainability, particularly concerning funding, that must be addressed to ensure the longevity of this endeavour.

I have been a member of the APCONF organising committee since 2011, although my role - helping with the online conference proceedings, and later, maintaining the conference website - did not require involvement in most of the major decision-making aspects of the committee. This position has thus provided me the luxury of being able to observe and be involved as both an organiser and a researcher in the field of Asian maritime archaeology, while simultaneously distancing me from much of the day-to-day preparations leading up to the actual conference. I have also been fortunate to be able to be in contact with many of the pivotal players in the APCONF, particularly the past and current committee chairs, and for this article I relied heavily on their input and recollections about the history of the conference to supplement my observations. In the interest of time, I was unable to interview all of the past and present committee members, and so it should be understood that the below comments represent individual opinions and feedback, and are not necessarily the opinions of the committee(s) as a whole.

\section{CONFERENCE ORIGINS}

The APCONF had its genesis in the serendipitous meeting of Dr. Mark Staniforth, then-graduate student Jun Kimura (both at Flinders University at the time), and Bobby Orillaneda of the National Museum of the Philippines. According to Kimura, around 2009, Flinders University had begun to be more involved in capacity building for the preservation and protection for regional UCH. Training was conducted under two auspices: (1) the Flinders Australian Leadership Awards, funded by the Australian government, and (2) UNESCO foundation courses. Staniforth, Orillaneda, and Kimura all happened to be leaders at a UNESCO training session in Thailand, and began discussing conference opportunities as they were seated together one day. While numerous maritime-related conferences took place globally, they were often situated in Europe, America, or Australia. The three men agreed that maritime archaeologists situated in the Asia-Pacific region often found 
attending those conferences challenging, as travel could be expensive and time-consuming (Mark Staniforth, email message to author, 25 June 2020). They recognised the need not only for additional training opportunities in the Asia-Pacific region, but also to create a platform for professionals in the region to meet and exchange ideas (Jun Kimura, email message to author, 19 June 2020). Had these three men not met, it is entirely possible that the APCONF would never have occurred.

From the outset, the conference was meant to welcome professionals from all areas of UCH management, including archaeologists, museum professionals, conservators, government employees, and more. Staniforth and others recognised that even if the conference was geographically accessible and relatively inexpensive many would still find it cost-prohibitive. In particular, they wanted to welcome students and other early career researchers, many of whom typically have only limited access to travel funds from their respective institutions. The organisers decided there should be a concerted effort to fund attendance for these constituents (Staniforth, email message to author, 25 June 2020). This was one of the many double-edged aspects of the APCONF. Providing additional funding for attendees was tremendously helpful and widened the participant base noticeably, but it would also present more challenges when considering funding for the conference overall.

That welcoming nature posed other additional complications to the organising of the conference as well. As Kimura pointed out, "Professionals could include 'professional' salvage companies" (Kimura, email message to author, 19 June 2020) - and salvage is, of course, the antithesis of careful archaeological investigation. The organisers needed standards to keep the promotion of ethical archaeological techniques at the heart of the gathering, and therefore decided to follow the policies and principles set out by UNESCO's 2001 Convention on the Protection of the Underwater Cultural Heritage. The Convention established the basic principles for the protection of UCH as well as "widely recognised practical rules" for its treatment and research (UNESCO 2017). These rules provided the conference some safeguards and kept the papers focused on exploring ways to support preserving and protecting $\mathrm{UCH}$ rather than simply recovering it for profit. The APCONF would thus be a suitable venue for discussions of ethical treatment of UCH as a shared cultural asset. It also would be an ideal forum in which country delegates could discuss the potential ratification of the Convention. When the idea of the APCONF was first germinating in 2009, only one country in the Asia-Pacific region had ratified the Convention. ${ }^{2}$ 
A gathering such as the proposed APCONF would provide opportunities to promote ratification to the attendees.

The first APCONF took place two years after the initial meeting between Staniforth, Kimura, and Orillaneda. The organisers determined that the ideal host institution was one that took underwater archaeology seriously as part of their mission, and the National Museum of the Philippines was eager to improve their endeavours in that field (Kimura, email message to author, 19 June 2020). Orillaneda and Dr. Ligaya Lacsina (Maritime and Underwater Cultural Heritage Division at the National Museum of the Philippines), who both worked at the museum, were interested in helping to organise the conference, and with then-Museum director Jeremy Barnes' approval agreed to be the local organiser. Staniforth, Kimura, and Orillaneda agreed that the first conference needed to be somewhere in Southeast Asia to help keep flight costs affordable for all participants with reasonable accommodations, and a local group of enthusiastic organisers. Manila fit the bill on all counts.

The first APCONF welcomed 128 delegates from 35 nations to the National Museum of the Philippines, and offered three plenary talks, 80 presentations, and 20 posters. They met their goal of welcoming and encouraging the next generation of researchers. The delegates included nearly 20 graduate students in addition to a number of other early career researchers, some of whom were presenting their first-ever academic paper at this conference (APCONF 2011). In Staniforth's words, the conference was particularly successful because "everyone was working in the same or similar field (not a small group within a much larger conference)" (Staniforth, email message to author, 30 June 2020). This allowed for more fruitful exchanges overall. As a researcher in this field, I came away from that first conference thinking that after often being the lone Asian specialist at an archaeology conference, or the sole archaeologist at an Asian studies conference, I had finally found a group of people who understood the common backgrounds, challenges, and interests in working on the UCH of the AsiaPacific region.

While there had been no initial guarantee that the conference would be anything but a one-off, there was enough enthusiasm that the gathering has reconvened every three years. Subsequent meetings were hosted at the University of Hawai'i at Manoa, Honolulu, USA, in 2014 and at the Hong Kong Maritime Museum in 2017. The global coronavirus pandemic has postponed the 2020 meeting that was scheduled for Taiwan. ${ }^{3}$ 


\section{CONFERENCE MEMBERSHIP AND PARTICIPANTS}

Unlike many professional conferences, which draw on a body of members and their dues to fund and participate in the conference, the APCONF has no associated organisation. While partly due to the scholarly and voluntary nature of the conference's beginnings, in which the three individual organisers were relying on their own networks and associations that they could involve in the conference, to date, it has been a deliberate decision to continue without an associated organisation. The original organisers envisioned that the conference should not be annual, as it needed to coordinate with other conferences without overlap. It needed to be able to move around within the Asia-Pacific region without being tied to one location. At least initially, a changing conference leadership and a flexible participant group facilitated that movement more easily. Kimura noted that other successful conferences, such as the World Archaeology Conference (WAC) and the International Congress for Underwater Archaeology (IKUWA), also follow aspects of this model to no detriment (Kimura, email message to author, 19 June 2020).

Hans Van Tilburg, organiser of the 2014 APCONF in Hawaii, also appreciated the flexibility that the open participation allows. When considering which aspects of the original conference to maintain in the second iteration, he specifically noted that the "non-official nature" of the group is "supportive of broad and diverse participation," as it allows for students and professionals from many related fields of study to find an academic home at that conference (Hans Van Tilburg, email message to author, 17 June 2020). Indeed, the conference series attendance has remained relatively steady since its inception, indicating that it has not suffered from its non-membership model but also has not grown substantially. Following the first meeting, with 128 delegates from 35 nations, the second meeting in Hawaii (2014) welcomed 139 participants from 27 countries, and Hong Kong (2017) hosted 115 participants from 26 countries. ${ }^{4}$

Van Tilburg acknowledged that while the non-official nature of the conference is one of its greatest strengths, it also presents one of the major challenges to conference organisation: no fixed membership means no stable membership fees or funds that can be earmarked for the conference (Van Tilburg, email message to author, 17 June 2020). In addition, Staniforth noted that conferences in Asia have become more common, pointing at competing attendance with triennial meetings hosted by Southeast Asian Ministers of Education Organization, Regional Centre for Archaeology and Fine Arts (SEAMEO-SPAFA), the Indo-Pacific Prehistory Association (IPPA), and 
others (Staniforth, email message to author, 30 June 2020). As there is a different conference every year, then, attendees may choose only one of these conferences instead of only attending the APCONF. A membership-based organisation might potentially build the attendance base, providing a sense of ownership in the organisation that does not currently exist, as well as securing a stable funding source for the conference. ${ }^{5}$

\section{CONFERENCE ORGANISING COMMITTEES: PROGRAMME AND LOCAL COMMITTEES}

Bill Jeffery, co-chair of the organising committees for the Hong Kong and Taiwan conferences, noted a further problem with the nebulous membership of the conference: issues with creating an effective organising committee itself. While to date it has been made up of a few dedicated volunteers, the committee is not an elected body, nor has the membership changed drastically since the inaugural APCONF, save for the fact that several of the initial members have stepped down from their leadership roles. Staniforth has not been involved in conference leadership since the original iteration, partly to allow earlier career researchers to be able to make their mark on it instead (Staniforth, email message to author, 22 September 2020). Orillaneda, as onsite coordinator for the Manila conference, also did not return to the wider conference organisation. As of the 2020 conference, Kimura stepped down from co-chair to become advisor to the conference as well.

The nature of the organising committee has changed over the course of the three completed (Manila, Hawaii and Hong Kong) and the fourth planned (Taiwan) meetings. As noted above, the Manila meeting was done with the strong cooperation of the National Museum of the Philippines, with Orillaneda working as the on-site coordinator and Staniforth and Kimura working as external coordinators. Other organising committee members, including myself, joined later in the process to help with other specialised aspects of the conference such as creating proceedings publications and establishing an online presence. The proceedings were of particular importance to Staniforth. Generally, however, the committee roles were informal and relied greatly on the individual's own goodwill and interest in ensuring the conference's success.

By the time of the 2017 conference in Hong Kong, the committee had expanded and delineated more formal roles. That year's committee members drafted and approved a conference manual for the first time after the 
conclusion of that meeting. Formally defined programme and venue committees, with the chairs of each serving on both committees, have grown out of the original division of labour taken on by the on-site and external coordinators from the first conference. The chair (or, as has been the case in the most recent conferences, co-chairs) of the programme committee is responsible for managing all programme and academic aspects of the conference, including the coordination of theme and programme selection. Other main positions in the programme committee include the UNESCO representative, website coordinator, online and printed publication leads, and a regional liaison coordinator. The publication leads and regional liaison coordinator head subcommittees of the same names, and additional subcommittees include groups who determine awards (best papers and posters) and travel assistance recipients. Members of the programme committee and its related subcommittees do not need to be from the venue country, and indeed the programme manual encourages diversity in ethnicity and cultural background to ensure a broad regional representation (APCONF 2018: 4). Currently, there is no language in the manual that emphasises gender diversity as well. Although the founding members of the APCONF were all male, in practice female members of the organising committee, including the regional liaisons, have averaged about $40 \%$ of the committee's total numbers. ${ }^{6}$

As there is no formal membership body, the regional liaisons play a critical role in disseminating information about the conference, soliciting paper and poster submissions, and encouraging interested parties to attend. They are also encouraged to solicit local sources of support for the conference. Again, the conference could not exist without this kind of cooperation, and as such relies greatly on the regional liaisons and their local networks. This may have been at the root of another shift in the process of selecting locations for the conference. For the earlier conferences, the organising committee was proactive in reaching out to potential organisations to gauge interest in becoming the host institution, while being mindful of the desire to vary the geographic location. By the time discussions began for the 2020 site location, there was enough interest from several groups that a formal bid process was instituted. As the regional liaisons worked to extend their local networks, it may have led to more groups taking initiative to host the APCONF.

This growing regional interest, and indeed the need to have strong local support to have a successful conference, has also helped formalise the role of the venue committee. The manual notes that the committee members "should be employees of that host country/institution, though efforts may be 
supplemented by volunteers or associates. Their expertise and knowledge and connection to local networks and facilities are crucial factors in the success of the APCONF event" (APCONF 2018: 4). Jeffery, who was co-chair of both the Hong Kong and Taiwan conferences, attests to the truth of that statement. The 2017 conference, hosted at a relatively small museum with limited staff, was less successful at mobilising local long-term interest. This resulted in some funding constraints detailed below, as the venue committee did not secure the wide range of sources necessary to fully fund as many participants as had happened in the past. The 2020 Taiwan committee, on the other hand, formally gave the local community more roles and responsibilities from earlier on in the process, culminating in a more invested venue committee and more direct support for the conference itself (Jeffery, email message to author, 22 June 2020).

After co-chairing the conference twice, Jeffery mused that it may be useful to consider establishing a "term limit" type of system that would get "new, keen blood" involved with the organisation (Jeffery, email message to author, 22 June 2020). Certainly, the committee is eager to have more people involved in the process, and indeed will need enthusiastic organisers if the conference is going to continue. It may, however, appear to those outside of the committee that it is hard to break into that structure without someone already on the committee actively inviting them. While the committee does regularly put out a call for volunteers, much can change for an individual during the three-year period between conferences. Once-enthusiastic members may encounter unforeseen external pressures that prevent their participation, or, conversely, they may find themselves able to take on more than they had previously anticipated. A formal membership base with a procedure for nominating and selecting committee members may make it easier to give newer members, especially a voice in the proceedings, as without that infrastructure they may feel less empowered to take on leadership roles.

\section{CONFERENCE FUNDING}

Funding the APCONF is a constant and critical issue. For a conference that recurs every three years, with no fixed membership or organising committee, no physical organisational office, and no built-in income, it is imperative to secure external funds. The composition of the organising committee, the local enthusiasm for the conference, and the overall affordability of the conference location all are factors. 
Kimura noted that obtaining grant money for the first conference was perhaps the greatest hurdle, "otherwise the conference would die just as an idea and never happen" (Kimura, email message to author, 19 June 2020). At the time, he was the treasurer for the Australasian Institute of Maritime Archaeology (AIMA), and worked with the then-President of AIMA, Ross Anderson, to apply for a UNESCO Australia grant to fund the conference. Staniforth, too, applied for and received a number of grants from institutions such as the Wenner-Gren Foundation and SEAMEO-SPAFA. The National Museum of the Philippines also provided financial assistance for the inaugural conference. In deciding that the conference venue should move from region to region, Staniforth remarked that this too would help with securing funding: instead of needing to apply for grants annually to the same organisations, in theory it would only be necessary to return to the same funding source once every few decades (Staniforth, email message to author, 28 June 2020). Seven major sponsors were listed in the final press release from the 2011 conference (APCONF 2011). ${ }^{7}$ In keeping with the endeavour to provide conference access to those who might otherwise financially be unable to attend, the funding acquired helped subsidise 28 conference participants (22\% of all attendees) from ten different countries. The APCONF travel assistance subcommittee is mandated to select stipend recipients "in a fair manner, taking into account the planned sessions, cultural and geographic diversity, gender balance, academic/professional experience and accomplishments, and any applicable conditions which may be stipulated by individual sponsoring agencies or programmes" (APCONF 2018: 8). Generally speaking, participants from particular geographic regions are also prioritised. $^{8}$

This multi-organisational model set the standard for future conferences. For the 2014 Hawaii meeting, the organising committee secured grants from two federal agencies in the US, the National Oceanic and Atmospheric Administration (NOAA) and the Bureau of Ocean Energy Management (BOEM), which likely reflected the organiser's position with NOAA (Van Tilburg, email message to author, 18 September 2020). WennerGren Foundation and UNESCO grants also funded the Hawaii conference, and it received additional support from the University of Hawai'i as the host institution. Over USD38,000 of those funds-50\% of the entire 2014 conference budget (APCONF 2018: 8)-were used to provide travel subsidies for 25 participants (just under one-fifth of the total attendees of the entire conference) (Van Tilburg, email message to author, 17 June 2020). 
The conference website lists twelve major sponsors, who provided financial support, and 48 supporting organisations, who "agreed with the aims of the conference and promoted and supported the conference," but did not necessarily help with conference funding (APCONF 2014a, 2014b). ${ }^{9}$ Securing funding in Hong Kong was more challenging, with only eight sponsors and 23 supporters (APCONF 2017a, 2017b). ${ }^{10}$ Jeffery noted that the APCONF 2017 committee was less successful in obtaining grants, particularly the WennerGren Foundation grant that had been a source of travel subsidies for attendees at the prior two conferences, and so only the two keynote speakers and seven conference delegates received any travel subsidies (full or partial) (Jeffery, email message to author, 26 July 2020).

This is another concern that may require the APCONF organising committee to consider creating a membership-based association affiliated with the conference, thus ensuring at least a small funding base. Even maintaining the conference website costs a modest fee, and to date organising committee members have often generously paid the fee through their personal accounts. Several past organisers commented that having an affiliated association and a permanent fiscal account may also help secure external grants, as it would more easily allow other organisations to formally recognise the group (Jeffery, email message to author, 22 June 2020, and Van Tilburg, email message to author, 17 June 2020). Kimura noted that for the inaugural conference, the Asian Academy for Heritage Management (associated with UNESCO in Bangkok, though not an active organisation) technically was the organiser, as that helped provide a recognisable institution affiliated with the conference (Kimura, email message to author, 19 June 2020). Jeffery, too, expressed the opinion that "we are not taken seriously" due to the absence of a formal membership-based organisation. Van Tilburg, however, went on to caution that "maintaining participation from resource-poorer locations like the Pacific Islands States will always require greater efforts [to raise funds]. The series should avoid the pitfall of becoming an event only attended by the wealthier nations..." (Van Tilburg, email message to author, 17 June 2020). Having a fee-based membership, even a minimal one, has the potential of "pricing out" early career researchers or possible attendees from developing locations who could most benefit from this type of conference. That being said, the committee is reviewing the possibility of becoming an accredited nongovernmental organisation (NGO), which could allow closer participation with other organisations and target improved integration of archaeology and cultural heritage management within the marine sciences (Van Tilburg, email message to author, 18 September 2020). 


\section{THE ROLE OF UNESCO}

The UNESCO UCH foundation training course set the stage for the original conference organisers' serendipitous meeting, and UNESCO has enjoyed a prominent role in the conference ever since. A representative from UNESCO is invited to sit on the programme committee to provide advice on regional issues (APCONF 2018: 5) ${ }^{11}$ As noted above, the principles and procedures laid out in the 2001 Convention on the Protection of the Underwater Cultural Heritage became the benchmark for conference participation. In addition, several of the organisers interviewed for this article mentioned that one of the original conference goals was to discuss support for and measures to increase ratification of the 2001 Convention. The Hawaii (2014) conference even had an entire session (with four papers presented) titled "UNESCO Convention on the Protection of the Underwater Cultural Heritage and International Cooperation". Indeed, while it is misleading to claim definitively that there is a direct link, three more countries in the Asia-Pacific region have ratified the Convention since the APCONF's inception (Chihiro Nishikawa, email message to author, 11 February 2021). ${ }^{12}$ It seems reasonable that at least some discussions at the APCONF about ratification contributed to that result.

Yet, some of the conference organisers expressed disappointment with what they viewed as UNESCO's lukewarm support for the APCONF's endeavours. Staniforth had hoped that UNESCO would be a full-fledged partner for the inaugural conference, not simply associated with a largely inactive commission within the regional Bangkok office. He even appealed to UNESCO to hold their regional Experts' Meeting in conjunction with the APCONF, which would both encourage conference attendance around that meeting and bring more potential experts to UNESCO's table, but UNESCO continues to this day to hold Experts' Meetings independent of the APCONF (Staniforth, email message to author, 28 June 2020). That is not to say that UNESCO was uninvolved at the APCONF. Three sessions at the 2014 meeting were organised by UNESCO (APCONF 2014c). Jeffery described the APCONF as being "sidelined" by UNESCO in Hong Kong, noting the lack of discussion there about ratifying the Convention. He also remarked that prior to the Hong Kong conference, UNESCO was involved in organising additional maritime archaeology events, notably having a heavy presence at the Perth IKUWA conference in 2016- and yet no major UNESCO sessions were planned at the 2017 APCONF, which has been the only conference based specifically on maritime archaeology of the wider Asia-Pacific region (Jeffery, email message to author, 22 June 2020). He further commented 
that while the Bangkok office was supportive of the Hong Kong and Taiwan conferences, even going as far as to promote the latter even when UNESCO cannot be formally involved, other regional offices have been less so, and central support from the Paris office is notably absent. Retired UNESCO staff member Etienne Clement noted, however, that severe budget cuts in staff travel costs and overall budget restrictions at UNESCO limited UNESCO attendance at the Hong Kong conference as well (Etienne Clement, email message to author, 28 August 2020).

That is not to say that UNESCO provides no other resources for the APCONF generally. Through AIMA, UNESCO Australia did provide funding for the inaugural conference, and the Hawaii meeting received financial support from UNESCO as well (Kimura, email message to author, 19 June 2020; Van Tilburg, email message to author, 17 June 2020). Jeffery also acknowledged that in conjunction with the Hong Kong conference, UNESCO did help organise an excursion to the Nanhai No. 1 shipwreck museum in Guangdong province. Participants were able to attend the International Symposium on the Discovery and Research of Nanhai No. 1, which was supported by the UNESCO Secretariat of the 2001 Convention. ${ }^{13}$

Post-conference collaborations relying on connections made between individuals at the APCONF and UNESCO also have come to fruition. Clement noted that there was a successful collaboration between the APCONF and UNESCO at the UN Conference for Small Islands Countries in Samoa (2014), where several meetings and workshops were organised with key APCONF committee members in leadership roles (Clement, email message to author, 28 August 2020). Several publications, including a study on UCH-related laws and training programmes in the Pacific, were edited by APCONF committee members, and those publications are available on the UNESCO Digital Library (UNESCO n.d.). Individual interactions between members of UNESCO and the APCONF may continue to lead to more sustainable developments in the future.

Establishing clear connections that encourage discussion of international cooperation and sustainability can be critical to ensuring UNESCO participation in what is often an academic-heavy conference. Clement suggested that a memorandum of understanding be negotiated between the APCONF and UNESCO for mutual benefit to help facilitate that interaction (Clement, email message to author, 28 August 2020). Once again, the APCONF may need to consider formalising its structure as an organised association to simplify that process. 


\section{APCONF PUBLICATIONS}

One of the goals of the original APCONF was to have a tangible, enduring result from the conference. Many academic conferences are ephemeral, with no way to reference details of the presentations once the conference is complete. If a proceedings volume is produced, it is often after the fact and is not comprehensive. From the outset, the APCONF wanted to preserve the information introduced at the meetings. Thus, there are two positions on the programme committee, the printed publication and online publication leads, who are responsible for obtaining written versions of the papers well in advance of the conference itself.

For the first two conferences, the papers were edited and compiled into a single printed volume that was distributed at the meeting. There was also a concerted effort on the part of the committee to donate hard copies to major regional archives and libraries. At the third meeting in Hong Kong, it was decided to forego a mass printed edition of the proceedings and instead provide each attendee with a flash drive on which all the papers were loaded. ${ }^{14}$ The reasons for this change were largely pragmatic. Printing a paper copy to distribute at the conference required submissions well in advance of the meeting, while soft copies could be edited and compiled almost until the actual meeting itself, allowing presenters more time to submit their work. The printed tomes were large and heavy, and as restrictions on baggage weights increased over time, it became problematic for some attendees to transport them home. The trade-off, however, was some technical issues with the flash drives that corrupted the files. For the Taiwan conference, the organising committee intends to provide a printed copy to all attendees.

To distribute the conference information even more widely, conference organisers decided to also provide an online version of the papers. The nonprofit Museum of Underwater Archaeology (http://www.themua.org) agreed to host the proceedings free of charge. ${ }^{15}$ Nearly all of the posters and papers presented at the last three meetings have been digitised and collected in these online proceedings, and are available to the public. In addition, beginning with the Hawaii conference, session organisers, keynote speakers, and the conference organisers provided brief video introductions. While to date it has not been possible to record and broadcast the entire conferences, these short clips allow the viewer more insight into the goals of the sessions and the conference itself. As of August 2020, the cumulative body of papers, videos, and posters from the three conferences have been viewed approximately three million times. 
The COVID-19 pandemic raised the possibility of turning the 2020 Taiwan conference into a virtual one, as so many other organisations have chosen to do. This would potentially create a video archive of the entire conference. However, the organising committee is cognisant of the restrictions on internet infrastructure for many of the island nations that often send representatives to this conference. Bandwidth can be limited, making virtual participation nearly impossible. In keeping with the original conference's goals of being inclusive and, especially, accommodating those students and researchers who may not be able to attend conferences even in non-pandemic times, the committee decided to postpone the meeting until attendees will be able to travel again. While from an archival perspective it would be ideal to have a video record of all conference presentations, having only video presentations instead of a physical conference does not meet the APCONF's goals.

\section{RESEARCH TRENDS OF THE APCONF}

We now turn from the organisational aspects of the APCONF to the content of the material presented. While it is impossible in the scope of this paper to do a thorough analysis of the various papers and posters, we can get a sense of some of the past decade's trends in UCH studies of the Asia-Pacific region by considering the conference themes, the types of sessions organised, and the titles of the papers submitted. The following analyses will include information from the Taiwan conference as it had been planned for March 2020 , although it should be acknowledged that when the conference does convene in November 2021, there may be some changes according to the circumstances of the planned presenters.

The first two meetings did not have specific overarching conference themes, but did suggest some broad sub-themes (e.g., "indigenous cultural heritage" or "regional underwater archaeology") meant to inspire potential session organisers. Both the 2017 and 2020 conferences chose to have a particular theme, and both times the programme committee highlighted the concept of the maritime cultural landscape. ${ }^{16}$ This seems to fit with the overall thrust of the APCONF, embracing not just shipwreck archaeology but also wider concepts of maritime infrastructure, coastal settlements, conservation and interpretation, and all the issues related to $\mathrm{UCH}$. 
The ever-widening focus of the conference is also visible in the types of sessions organised. Forty-nine sessions have been planned over the span of the four conferences. Some topics have remained consistent: all of the conferences have had dedicated sessions on regional underwater archaeology in East Asia, Southeast Asia, and Spain and the Asia-Pacific region (including the Manila Galleon trade), as well as museums and site interpretation. Most of the conferences have also included sessions specifically on war and conflict, ceramics, conservation of wet materials, Pacific Islands UCH, and South Asian/Indian Ocean UCH. One change over time, however, has been the gradual specialisation of some of the sessions. For example, in 2011 there was a session titled "The archaeological study of ships' cargo, hull, and maritime infrastructure". This is a quite inclusive and non-specific session title, and the 14 papers in that session alone ranged geographically from Australia to Korea to the Philippines to Africa (and everywhere in between), and temporally from the prehistoric period to the 20th century. The 2020 conference, on the other hand, planned to have sessions on such focused topics as a single ship (for example, the Chinese junk Free China), and has expanded the geographic range of the conference to include for the first time a session solely on Arctic maritime archaeology. As interest and participation in the conference grows, so does the luxury of greater specialisation.

An analysis of paper titles also yields information about the shifting foci of UCH studies. This is not comprehensive, as occasionally paper titles can be ambiguous or do not fully reflect the contents presented. It can, however, provide a glimpse into some of the changes and continuities in these studies, and reflects the growing specialisation indicated in the session titles. ${ }^{17}$ Throughout the span of the conferences, by far the most common trend was to analyse a specific, single shipwreck or other UCH site (78 papers). The number of papers was relatively consistent each year, with 17 papers in the 2011 conference naming a single site in their titles, and 23 papers doing so for the 2020 conference. Multi-site (shipwreck or other UCH) papers were also common (66 papers), though after the peak of 23 such papers in 2014 the numbers have dropped to 16 or 17 in the past conferences. Topics on trade, shipping, and exchange yield steady submissions, with about 26 papers over the four conferences. Military sites are also common subjects, split almost evenly between World War II sites (20 papers), and all other battlefield or military sites (20 papers). Museum work (including $\mathrm{UCH}$ centres and education efforts) and site management/interpretation have also remained steady (33 papers), albeit with a spike in papers on social media and film in the first and fourth conferences that may reflect wider changing technological trends. 
Twenty-seven total papers focused on conservation of various materials from underwater sites and/or in situ ship preservation were also relatively evenly distributed throughout the four conferences.

There seems to be a gradually decreasing interest in the need for legal and physical protection of sites, which may reflect the concerns noted above about the lack of UNESCO involvement. While the second most common category focused on preserving or protecting $\mathrm{UCH}$, including efforts to train interested parties in these matters (48 total), that number dropped by more than half from 16 papers in 2011 to only seven in 2020. Papers on legal protection, as well, dropped noticeably from 2017 to 2020, with only three papers scheduled as opposed to the prior year's eight. ${ }^{18}$ The first three conferences had one paper each addressing ethical questions, but none were scheduled for the 2020 meeting, though there was one focusing on repatriation of artefacts that may fall into this category. Part of this decline may stem from the fact that UNESCO cannot participate in the Taiwan conference; several of the sessions addressing these topics in prior conferences were organised under UNESCO auspices. It will be worth observing whether this trend reverses if the fifth APCONF is held in a region that allows UNESCO participation.

Geographic trends are also visible through the paper titles. Note that this is from the titles alone, and thus may not comprehensively treat the topics discussed in all papers, and additionally does not necessarily indicate the nationality or institutional affiliation of the presenters. Even with those caveats, however, certain tendencies are apparent. Perhaps unsurprisingly, there is a direct correlation between the location of the conference and the number of papers concerned with sites in direct proximity. ${ }^{19}$ The only exception to this rule has been in participation from the Philippines, which enjoyed relatively consistent representation for the first three meetings (six papers each) but dropped to only one scheduled for 2020. Topics from Indonesia, China (excluding specifically Taiwan or Hong Kong), Japan, and India have been the most numerous, with each country being the topic of between 32 and 34 papers submitted among all four conferences. With that being said, except for India, the numbers for each of those countries have increased dramatically over the past decade. Only three China or Japan-related papers were presented at the 2011 conference, but those numbers increased threefold (nine and 10 papers, respectively) for 2020. Indonesia's numbers doubled, from six in 2011 to 13 in 2020. Topics on India have remained relatively stable with the exception of 2017, when visa and/or cost obstacles prevented many from that region attending the conference and thus resulted in an exceptionally small number of papers. This of course relates back to the funding issues 
noted above, as travel stipends have a distinct impact on geo-topical selection (Van Tilburg, email message to author, 18 September 2020). It seems apparent that the other regions are experiencing increased interest and involvement in $\mathrm{UCH}$ pursuits, leading to proportionally increased participation in the APCONF.

Most other countries have enjoyed relatively steady representation throughout the conferences, with several exceptions. Australian numbers have been steadily declining from its peak of six papers in 2011 to only two scheduled for 2020. It is likely that the 2017 IKUWA meeting in Perth and the annual AIMA meetings detracted from Australia-based papers presented at the Hong Kong meeting (only a single paper), but this is a striking decline particularly considering the strong support from Australia for the inaugural conference. The South and Latin American representation (Peru, Mexico and Andes), which had been relatively restrained but consistent in earlier conferences, will be entirely absent in Taiwan. In contrast, recent conferences have seen a small but growing European presence, usually in the form of a comparative approach to UCH. Papers connecting Macedonian boatbuilding with traditions in Nagano (Japan) and Yunnan (China), or presenting the Viking Museum in Denmark as a case study using technology to present maritime culture, were two topics introduced at the 2017 conference. This may indicate a growing interest in the APCONF from a wider geographic audience.

A final note about research trends in the papers presented includes a growing focus on specific types of technologies and research methods. Keywords such as "photogrammetry," "geographic information systems (GIS)," "ethnoarchaeology," "maritime identity," and "archaeobotany" that were entirely absent from the first two conferences are more prevalent in papers from 2017 and 2020. The latter, in particular, has a number of papers focusing on searching for a particular wreck or site, suggesting a concentration on search techniques and technology. Finally, there has been a dramatic increase in non-shipwreck site-specific papers, mostly focusing on ports, wharves, and other marine-related infrastructure. This likely correlates to the growing interest in maritime cultural landscape studies, which was also reflected in the themes of the 2017 and 2020 conferences.

Taken together, then, the conference, session, and paper themes all reflect the evolution of the field as a whole. The inaugural conference aimed to bring members of government agencies, universities, non-governmental organisations (NGOs), intergovernmental organisations (IGOs), museums, 
the private sector, and the wider community together, and served as a focused regional introduction to the field. As interest and projects have increased, so too has the range of topics, sites, and approaches to the study of UCH.

\section{MOVING FORWARD: NOTING CONFERENCE OUTCOMES AND CHALLENGES}

The various APCONF meetings have yielded several tangible outcomes beyond the meetings themselves. In all instances to date, the APCONF has worked with host countries, organisations, and groups trying to safeguard $\mathrm{UCH}$. The National Museum of the Philippines is expanding and building an entire structure dedicated to maritime archaeology, in part inspired by interest generated from the inaugural conference (Kimura, email message to author, 19 June 2020). In Hawaii, the NOAA National Marine Sanctuaries Programmes has been active in detecting World War II remains, and the avocational Hong Kong Underwater Heritage Group has been working with the Hong Kong Maritime Museum. We hope as well that the APCONF has helped legitimise the achievements of these organisations and raise their local profiles (Kimura, email message to author, 17 September 2020).

Individual networking at these conferences has also been helpful. Staniforth noted that the Vietnam Maritime Archaeology Project (VMAP) was helped by contacts made at the first conference, and several participants later have gone on to more formal maritime archaeological study (particularly at Flinders University) partly due to connections through the APCONF (Staniforth, email message to author, 30 June 2020). A two-volume series edited by Maria Cruz Berrocal and Cheng-Hwa Tsang credits in part a session at the 2014 APCONF, and several of the participants in that session (author included) contributed essays to that volume (Berrocal and Tsang 2017: 7). As retired UNESCO staff member Clement pointed out above, key APCONF members also collaborated with UNESCO at the Small Islands Conference in Samoa in 2014, and of course, as noted earlier, nearly all of the papers and posters presented are available on the online archives at the Museum of Underwater Archaeology.

Yet, many of the previous conference organisers suggested that there is still so much more unrealised potential. Several pointed to workshops and site visits held in conjunction with the conference that could be expanded upon. ${ }^{20}$ Jeffery commented that ideally a field school or summer session might be 
organised under the auspices of the APCONF, but that would require the cooperation of a local school or organisation with good standing (Jeffery, email message to author, 22 June 2020). The topic of the UNESCO Convention also looms large, as several people suggested that even if participating countries have not ratified the document, its impact and scope still could be more of a focus within the conference. It should be noted, however, that even though the Convention remains unratified by many regions, countries can still benefit from it. Van Tilburg commented that numerous US federal resource management agencies, for example, have formally adopted the Convention Annex as Best Practices for the field (Van Tilburg, email message to author, 18 September 2020).

Realising these ideas and more will require sustained efforts by the APCONF organising committees and wider maritime archaeological community to grow and develop the conference. The broadening range of research topics presented at the APCONF suggests that there will be consistent interest in and the potential for expansion of the conference itself. Past organisers point out the strengths of the conference's broad inclusion of maritime heritage topics, including indigenous cultural heritage, sustainability and environmental concerns, and community engagement. There is a vast repository of expertise and interest in the region available to be tapped; it is a matter of finding the best way of energising that community most effectively. Indeed, that word is what Jeffery returns to: "community" as necessary for continued success, as increased commitment from the wider maritime archaeological community will help grow additional tangible opportunities from the conference (Jeffery, email message to author, 22 June 2020).

All, however, hope that the conference continues and thrives. Each meeting has built on the last, as reflected in the ever-expanding diversity of paper topics and the increasing numbers of participants. Our global network widens via this regional focus. Van Tilburg has perhaps phrased it best as we look toward the conference's future: "[The APCONF] is a rare opportunity to meet with colleagues from across the very broad and diverse region, on common ground within the $[\mathrm{UCH}]$ preservation field, sharing related experiences and insights that reveal how, within the maritime realm, there is more that unites us than divides us. And it's quite a lot of fun" (Van Tilburg, email message to author, 17 June 2020). 


\section{ACKNOWLEDGEMENTS}

I deeply appreciate the time and effort that conference organisers Mark Staniforth, Jun Kimura, Hans Van Tilburg, and Bill Jeffery have devoted not only to answering my many questions, but also for their work and all those who have contributed to the APCONF itself. It truly has been something I am grateful to have been a part of. I also thank Etienne Clement and Chihiro Nishikawa for their input on UNESCO's involvement in the conference and on the ratification of the 2001 Convention. Robert Hinck generously provided me with additional information on organisational communications theory that was helpful both for this article and in thinking about how the APCONF organisation can move forward. T. Kurt Knoerl's comments on a draft of this article have made it stronger, and his work on the Museum of Underwater Archaeology has created an invaluable repository of information on AsiaPacific UCH. I am always grateful for his support in all I do.

\section{COMPLIANCE WITH ETHICAL STANDARDS}

The author has received permission from all parties quoted in this article to use the email contents cited throughout.

\section{NOTES}

* Michelle Damian, PhD (University of Southern California), began working as an Assistant Professor at Monmouth College, IL, USA, after a year as a postdoctoral fellow at the Reischauer Institute of Japanese Studies at Harvard University. She specialises in Japanese maritime history and archaeology, and is the author of several articles and book chapters. Damian has worked and studied in Japan for over nine years, including 18 months as a Fulbright fellow. Her current research focuses on 14th to 16th century Japanese maritime-based trade networks, tracing the movements of both people and commodities in the Seto Inland Sea region. She is also on the Board of Directors for the non-profit Museum of Underwater Archaeology (www.themua. org).

1 The conference manual defines the Asia-Pacific region as follows: "For the purposes of this conference series, the broadly defined Asia-Pacific region includes all maritime geographic areas between the Indian and Pacific Oceans, including Indian Ocean rim countries, Southeast Asia, mainland and eastern Asia, Pacific Rim countries, and Oceania Island states" (APCONF 2018: 10).

2 Cambodia had ratified the Convention in 2007. 
3 This conference was originally supposed to take place in March 2020, but the disruptions in international travel presented by the COVID-19 pandemic postponed it first to November 2020, and at the time of this writing it has been rescheduled again to November 2021.

4 At the time of writing, attendance for the Taiwan conference was uncertain due to the global pandemic.

5 It is not unusual for informal organisations to morph into a more formal institution in this manner, of course. Institutionalisation occurs when a taken-for-granted pattern of practices and communication is established (Lammers and Garcia 2017), and as we see here, the APCONF has begun to create those patterns of practices through documents such as the conference manual. The degree to which that institutionalisation will continue, however, remains to be seen.

6 This is based on the organising committee lists for each conference noted on the APCONF website.

7 Sponsors included UNESCO, the Australian National Commission for UNESCO, the Australian Federal Government's Department of Sustainability, Environment, Water, Populations, and Communities, The Wenner-Gren Foundation, SEAMEO-SPAFA, the Australasian Institute for Maritime Archaeology, and the Korean National Institute of Maritime Cultural Heritage.

8 For the 2014 conference, for example, the following countries were considered "List A countries", and List B countries - all countries not listed in List A-were particularly eligible for stipends. List A: Australia, Brunei Darussalam, Canada, European Union countries, Hong Kong, Israel, Japan, Liechtenstein, New Zealand, Norway, Singapore, South Korea, Switzerland, Taiwan, USA (APCONF 2014d).

9 Sponsors included the National Marine Sanctuary Foundation, the NOAA Maritime Heritage Program, the Wenner-Gren Foundation, BOEM, UNESCO, the Australasian Institute of Maritime Archaeology (AIMA), the Ocean Foundation, Ships of Discovery, SEAMEO-SPAFA, University of Hawai'i Manoa, Field Museum of Natural History, and Maney Publishing.

10 Sponsors included the Hong Kong Maritime Museum, the Taiwan Bureau of Cultural Heritage, Ministry of Culture, AIMA, Department of Chinese and History of City University of Hong Kong, Chinese University of Hong Kong, National Research Institute of Maritime Cultural Heritage, Tokai University, and the University of Guam.

11 The manual also notes that "When APCONF engages with countries/institutions not part of or supported by UNESCO, the UNESCO representative has the option to temporarily stand down from the conference committee". That will likely be the case for the Taiwan meeting.

12 Iran ratified the convention in 2009, the Federated States of Micronesia in 2018, and Niue in 2019.

13 I myself attended that excursion and was extremely appreciative of the opportunity provided not only to visit the museum and see the shipwreck conservation in progress, but also to hear the additional current research on the wreck.

14 Some copies of the proceedings have been printed, but not widely distributed (Jeffery, email message to author, 26 September 2020). 
15 Direct links to the conference proceedings are: 2011 Manila (http://www.themua.org/ collections/collections/show/2), 2014 Hawaii (http://www.themua.org/collections/ collections/show/13), and 2017 Hong Kong (http://www.themua.org/collections/ collections/show/40).

16 For 2017, the theme was "The Maritime Cultural Landscapes and Seascapes of AsiaPacific: Voyaging, Migration, Colonisation, Trade, and Cross-Cultural Contacts", and in 2020 it was "The Maritime Cultural Landscape of the Austronesian Diaspora".

17 This analysis includes 399 papers accepted for the conferences from 2011-2020, including plenary and keynote speeches when available. Due to some participants not being able to attend various conferences, it is possible that not all papers were actually presented at the conference. Keywords included subjects such as geographic location, type of site, methodologies, and general concepts. Furthermore, a single paper could have multiple keywords: for example, a paper entitled "Potential for Spanish Colonial Archaeology in the Northern Mariana Islands" would have the keywords "colonisation", "Mariana Islands", and "Spain" associated with it, while "History and Current Status of Underwater Cultural Heritage in Cambodia", without more specific identifiers, simply has the keyword of "Cambodia".

18 Twenty total such papers have been accepted over the course of the four conferences.

19 Of the 33 papers indicating a topic on China, nearly half (14) were presented at Hong Kong in 2017, and the next greatest number (nine) scheduled for Taiwan in 2020. Similarly, nine papers in Hawaii addressed Hawaiian UCH; it was the only conference to have any papers specifically on those islands. For 2020, Taiwan saw papers related to its UCH triple all of the submissions for prior conferences ( 15 of the cumulative 20 papers on Taiwanese UCH).

20 Van Tilburg remarked on an in situ preservation workshop organised by the Western Australia Museum at the Hawaii conference (email message to author, 17 June 2020), and Jeffery (email message to author, 22 June 2020) noted the success of the aforementioned site visit to the Nanhai No. 1 museum.

\section{REFERENCES}

APCONF (The Asia-Pacific Regional Conference on Underwater Cultural Heritage). 2011. Final press release. The Asia-Pacific Regional Conference on Underwater Cultural Heritage. http://www.apconf.org/wp-content/uploads/2011-FinalPressRelease-2. pdf (accessed 7 May 2021).

2014a. 2014 sponsors. The Asia-Pacific Regional Conference on Underwater Cultural Heritage. http://www.apconf.org/call-for/past-conferences/2014-apconfhonolulu/2014-sponsors/ (accessed 7 May 2021).

2014b. 2014 conference supporters. The Asia-Pacific Regional Conference on Underwater Cultural Heritage. http://www.apconf.org/call-for/pastconferences/2014-apconf-honolulu/2014-conference-supporters/ (accessed 7 May 2021). 
2014c. 2014 sessions. The Asia-Pacific Regional Conference on Underwater Cultural Heritage. http://www.apconf.org/call-for/past-conferences/2014-apconfhonolulu/2014-sessions/ (accessed 7 May 2021).

2014d. 2014 registration and fees. The Asia-Pacific Regional Conference on Underwater Cultural Heritage. http://www.apconf.org/call-for/past -conferences/2014-apconf-honolulu/2014-registration-and-fees/ (accessed 14 September 2020).

2017a. 2017 sponsors. The Asia-Pacific Regional Conference on Underwater Cultural Heritage. http://www.apconf.org/call-for/past-conferences/2017-apconf -hong-kong/2017-sponsors/ (accessed 7 May 2021).

2017b. 2017 supporters. The Asia-Pacific Regional Conference on Underwater Cultural Heritage. http://www.apconf.org/call-for/past-conferences/2017-apconf -hong-kong/2017-supporters/ (accessed 7 May 2021).

2018. The Asia-Pacific Regional Conference on Underwater Cultural Heritage series: Conference planning process: Roles and procedures. Unpublished manual.

n.d. The Asia-Pacific Regional Conference on Underwater Cultural Heritage. http://www.apconf.org (accessed 7 May 2021).

Berrocal, M. C. and Tsang, C. H. 2017. Historical archaeology of early modern colonialism in Asia-Pacific. Gainesville: University Press of Florida.

Lammers, J. C. and Garcia, M. A. 2017. Institutional theory approaches. The International encyclopedia of organizational communication, eds. Scott, C. R. et al., 1-10. https://doi.org/10.1002/9781118955567.wbieoc113

The Museum of Underwater Archaeology. 2004. MUA image and document collections. http://www.themua.org/collections/image-documents (accessed 7 May 2021).

UNESCO (United Nations Educational, Scientific and Cultural Organization). 2017. About the Convention on the Protection of the Underwater Cultural Heritage. http://www.unesco.org/new/en/culture/themes/underwater-cultural-heritage/2001 -convention/ (accessed 7 May 2021).

n.d. UNESCO digital library. https://unesdoc.unesco.org (accessed 7 May 2021). 